\title{
APLICAÇÃO DA METODOLOGIA SEIS SIGMA PARA REDUZIR O CONSUMO DE AMINA NA FLOTAÇÃO REVERSA DE MINÉRIO DE FERRO*
}

Fábio Lucas da Silva ${ }^{1}$ Rodrigo Alves dos Santos ${ }^{2}$

\begin{abstract}
Resumo
Com a queda brusca nos preços das commodities, os termos redução de custos e maior produtividade tornaram-se assuntos constantemente abordados no cotidiano das empresas, pois esses fatores representam questão de sobrevivência das organizações. Para tal, a busca por melhorar continuamente o processo produtivo em prol de garantir espaço no mercado é uma realidade e necessidade, com isto é importante que as empresas conheçam detalhadamente os seus processos e tenham maturidade para tomar decisões baseadas em dados e fatos. Assim, este trabalho tem como objetivo aplicar a metodologia Seis Sigma para investigar quais são as variáveis que mais influenciam no processo de flotação reversa de minério de ferro reduzindo o consumo do reagente coletor amina uma empresa de mineração na cidade de Itabira MG.
\end{abstract}

Palavras-chave: Amina; Flotação; Seis Sigma.

\section{Abstract}

SIX SIGMA METHODOLOGY APPLICATION IN REDUCING THE AMINE CONSUMPTION OF REVERSE IRON ORE FLOTATION

With the sharp fall in commodity prices, the terms cost reduction and higher productivity became issues that are constantly addressed in companies' daily life, since these factors represent a matter of survival of the organizations. To do this, the search for continuous improvement of the production process in order to guarantee space in the market is a reality and necessity, so it is important that companies know their processes in detail and have the maturity to make decisions based on data and facts. Thus, this work aims to apply the Six Sigma methodology to investigate which are the variables that most influence in the reverse iron flotation process of iron reducing the consumption of reagent amine collector a mining company in Itabira city, MG state.

Keywords: Amine; Flotation; Six Sigma.

1 Tecnólogo em Processos Gerenciais, Especialista em Gestão Empresarial, Analista Gestão Integrada, Gerência Qualidade e Saúde Sudeste, Vale SA, Itabira, Minas Gerais, Brasil.

2 Graduado em Engenharia de Produção e bacharel em Matemática, Especialista Tratamento Mineral, Supervisor Planejamento e Controle de Processo, Gerência Tratamento Minério Conceição, Vale SA, Itabira, Minas Gerais, Brasil.. 


\section{INTRODUÇÃO}

A variabilidade e incerteza de preços no mercado das commodities, como do minério de ferro, faz com que as empresas deste setor busquem cada vez mais reduzir os custos operacionais e agregar valor ao seu produto para atender as especificações do cliente. A unidade operacional de tratamento de minério de ferro estudada neste projeto está situada no município de Itabira/MG e contempla uma das grandes mineradoras do mercado mundial. O processo produtivo em estudo tem capacidade de produzir doze milhões de toneladas de pellet feed com teores de ferro próximo $68,5 \%$. Para alcançar esse elevado teor metálico é necessário beneficiar o minério de ferro, e dentre as etapas de beneficiamento, o escopo deste projeto restringe-se ao processo de flotação e as variáveis de influência em sua performance, e apresenta como indicador principal o consumo do reagente coletor amina.

A flotação é um processo de separação aplicado a partículas sólidas que explora a diferenças de propriedades de superfície entre as várias espécies presentes na polpa. Nos sistemas de flotação a fase líquida é sempre a água, uma espécie polar, e a fase gasosa é quase sempre o ar, constituído basicamente por moléculas apolares. Uma substância hidrofóbica é aquela cuja superfície é essencialmente apolar, tendo maior afinidade com o ar que com a água. Por outro lado, substância hidrofílica é aquela cuja superfície é polar, tendo maior afinidade com a água que com o ar (PERES, 1996). Para alterar a interface sólido/líquido e melhorar a separação são utilizados três tipos de reagentes químicos: coletores, depressores e modificadores de $\mathrm{pH}$. O reagente depressor utilizado na unidade operacional em estudo é o amido de milho/mandioca, como modificador de $\mathrm{pH}$ utiliza-se o hidróxido de sódio ou dióxido de carbono e coletor a amina. Uma das iniciativas dotadas pela unidade operacional para melhorar a geração de caixa foi a redução de custo por meio de projetos desdobrados do planejamento estratégico. Nesse contexto, a metodologia Seis Sigma, é implementada nas organizações como um programa de qualidade que permite operacionalizar a estratégia empresarial. Os projetos de melhoria dessa metodologia devem estar alinhados com os objetivos do negócio, de modo a contribuir para o desempenho dos critérios competitivos. Do ponto de vista operacional, a metodologia impulsiona a redução da variabilidade e dos defeitos, o aumento da capacidade, e a melhoria contínua dos processos (SANTOS e MARTINS, 2008).

Sendo assim, o objetivo principal deste projeto consiste em aplicar a metodologia Seis Sigma para reduzir o consumo de amina, definir quais são as variáveis que mais influenciam este processo, e assim reduzir o custo operacional na unidade operacional de Itabira. Em prol do alcance desse objetivo principal, têm-se as seguintes atividades-meio: definição do nível sigma do processo; análise estatística do processo (com fatos e dados); identificação das variáveis envolvidas no processo; priorização das principais variáveis; proposta de ações e verificação das ações implementadas.

\section{MATERIAIS E MÉTODOS}

\subsection{Metodologia Seis Sigma}

A metodologia Seis Sigma surgiu em 1987 na Motorola com o objetivo de aumentar a competitividade da empresa em relação aos concorrentes estrangeiros. Com a implementação do programa, ela se tornou líder do mercado, em 1988 ganhou o 
Prêmio Nacional de Qualidade Malcolm Baldrige, além de obter um ganho de 2,2 bilhões de dólares até o início da década de 1990 (PYZDEK e KELLER, 2012; WERKEMA, 2012). Para Andrietta e Miguel (2002), a metodologia surgiu para auxiliar, conquistar superioridade e obter bons resultados, pois o Seis Sigma concentra na diminuição/eliminação da incidência de erros, defeitos, falhas e visa reduzir a variabilidade para os eventos críticos. Na literatura, a visão da metodologia Seis Sigma, apresenta duas abordagens principais: a estatística e a estratégica. A estatística, o objetivo é quantificar a variação do resultado de um processo crítico e identificar o nível sigma. A estratégica, considera uma abordagem mais abrangente, e está interligada com a implementação de estratégias que melhoram o desempenho do negócio e o seu potencial competitivo (MARTINS e SANTOS, 2008). O método padrão seguido para aplicação da metodologia Seis Sigma é o ciclo conhecido como Definir-Medir-Analisar-Melhorar-Controlar (DMAIC - Define, Measure, Analyse, Improve, Control), em que as 5 etapas fornecem um modelo simples e estruturado para a melhoria de desempenho e alcance das metas de um determinado projeto (PYZDEK e KELLER, 2012; WERKEMA, 2012).

\subsection{O Método DMAIC e suas ferramentas}

Pande, Neuman e Cavanagh (2007) afirmam que dentre os possíveis métodos utilizados para a melhoria dos processos de uma organização por meio da aplicação do programa Seis Sigma, o DMAIC é a cada dia o mais usual. Essa sigla representa as 5 etapas principais do método: Define - Definir, Mesure - Medir, Analyse Analisar, Improve - Melhorar e Control - Controlar. De acordo com Werkema (2012) e Youssouf, Rachid e Ion (2014), o DMAIC é um método sistemático de resolução de problemas cujo as etapas integram diversas atividades e ferramentas, e que permite resultados confiáveis e o controle da qualidade dos processos. O Quadro 1 apresenta os pontos principais do método e algumas das ferramentas que podem ser utilizadas.

Quadro 1 - Pontos principais do DMAIC.

\begin{tabular}{|c|c|c|c|}
\hline Fases & Visão geral & Atividades relacionadas ao projeto & Ferramentas \\
\hline $\begin{array}{l}\text { 吊 } \\
\frac{\text { min }}{z} \\
\text { D }\end{array}$ & $\begin{array}{lr}\text { Definir } & \text { com } \\
\text { precisão o escopo } \\
\text { e objetivos } & \text { do } \\
\text { projeto } & \text { de } \\
\text { melhoria; } & \end{array}$ & $\begin{array}{l}\text { - Descrever o problema e definir a meta; } \\
\text { - Avaliar histórico do problema, retorno } \\
\text { econômico e impacto; } \\
\text { - Avaliar a prioridade do projeto; } \\
\text { - Definir participantes, escopo, cronograma e } \\
\text { recursos; } \\
\text { - Identificar as necessidades dos clientes; } \\
\text { - Definir o processo. }\end{array}$ & $\begin{array}{l}\text { - Mapa de raciocínio; } \\
\text { - Termo de Abertura do projeto; } \\
\text { - Métricas do Seis Sigma; } \\
\text { - Gráfico Sequencial; } \\
\text { - Carta de Controle; } \\
\text { - Análise Econômica; } \\
\text { - Voz do cliente. }\end{array}$ \\
\hline 䎡 & $\begin{array}{l}\text { Medir o processo } \\
\text { atual e determinar } \\
\text { a localização ou } \\
\text { foco do problema }\end{array}$ & $\begin{array}{l}\text { - Definir forma de coleta de dados; } \\
\text { - Avaliar Sistema de Medição; } \\
\text { - Identificar forma de estratificação do } \\
\text { problema; } \\
\text { - Definir e estudar problemas prioritários; } \\
\text { - Estabelecer metas para os problemas } \\
\text { prioritários. }\end{array}$ & $\begin{array}{l}\text { - Avaliação de Sistema de } \\
\text { Medição; } \\
\text { - Estratificação; } \\
\text { - Diagrama de Pareto; } \\
\text { - Carta de controle; } \\
\text { - Histograma; Boxplot; } \\
\text { - Índice de Capacidade. }\end{array}$ \\
\hline
\end{tabular}




\begin{tabular}{|c|c|c|c|}
\hline$\frac{\sum_{D}^{D}}{\frac{D}{D}}$ & \begin{tabular}{|lr} 
Analisar & o \\
processo & $\mathrm{e}$ \\
determinar & as \\
causas de & cada \\
problema & \\
prioritário; &
\end{tabular} & $\begin{array}{l}\text { - Analisar o processo e os dados do } \\
\text { problema prioritário; } \\
\text { - Identificar, priorizar e quantificar as causas } \\
\text { potenciais. }\end{array}$ & $\begin{array}{l}\text { - Fluxograma; } \\
\text { - FMEA; } \\
\text { - Brainstorming; } \\
\text { - Diagrama de causa-efeito; } \\
\text { - Teste de hipóteses; } \\
\text { - Diagrama de dispersão; } \\
\text { - Análise de Variância; } \\
\text { - Planejamento de Experimentos; } \\
\text { - Matriz de Priorização. }\end{array}$ \\
\hline 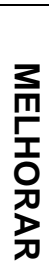 & $\begin{array}{lrr}\text { Melhorar } & & \text { o } \\
\text { sistema: } & \text { propor, } \\
\text { avaliar } & & \text { e } \\
\text { implementar } & \\
\text { soluções } & \text { par } & \text { a } \\
\text { cada } & \text { problema } \\
\text { prioritário; } & & \end{array}$ & $\begin{array}{l}\text { - Identificar soluções prioritárias; } \\
\text { - Avaliar e minimizar os riscos; } \\
\text { - Elaborar e executar um plano para } \\
\text { implementar as soluções. }\end{array}$ & $\begin{array}{l}\text { - Brainstorming; } \\
\text { - FMEA; } \\
\text { - Plano de ação: 5W2H. }\end{array}$ \\
\hline 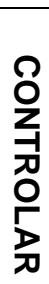 & $\begin{array}{l}\text { Controlar o novo } \\
\text { sistema, de forma } \\
\text { a garantir que o } \\
\text { alcance da meta } \\
\text { seja mantido a } \\
\text { longo prazo. }\end{array}$ & $\begin{array}{l}\text {-Avaliar se a meta foi alcançada; } \\
\text {-Padronizar e transmitir as alterações; } \\
\text {-Implementar um plano para monitoramento } \\
\text { da performance e tomadas de ações } \\
\text { corretivas caso surjam anomalias. }\end{array}$ & $\begin{array}{l}\text {-Procedimento Operacional } \\
\text { Padrão; } \\
\text {-Relatórios de anomalias; } \\
\text {-OCAP. }\end{array}$ \\
\hline
\end{tabular}

Fonte: Adaptado de Werkema (2012); Pyzdek e Keller (2011).

O Quadro 1 apresenta as atividades que devem ser realizadas em cada uma das fases do DMAIC. Para Pyzdek e Keller (2011) esse método fornece um "processo por portas", de modo que para finalizar uma determinada etapa e iniciar a próxima, todos as atividades devem ser concluídas. Para cada estágio do projeto deve-se usar as ferramentas apropriadas.

\subsection{Objeto de estudo}

O objeto de estudo da pesquisa é uma unidade operacional, localizada na cidade de Itabira, Minas Gerais, de uma mineradora. A empresa, que tem sede no Brasil, foi criada pelo o governo brasileiro em 1942, e hoje, apresenta atuação Global, e está presente em mais de 30 países. A organização exerce atividades relacionadas à mineração, logística, energia, siderurgia e trem de passageiros, sendo que, a mineração, com destaque para o minério de ferro, é o principal negócio da empresa. A unidade de estudo tem como atividade principal a produção do minério de ferro (Pellet Feed), e os seus macroprocessos diretos estão relacionados na Figura 1.

\subsection{Método de pesquisa}

O procedimento técnico utilizado nesta pesquisa foi a pesquisa-ação, que de acordo com Mello et. al. (2012) é caracterizado pelo envolvimento dos pesquisadores para a produção do conhecimento (termo pesquisa) alinhado a alteração intencional de uma determinada situação (termo ação), visando a solução de um problema. O que vai de encontro com o propósito desta pesquisa, que é aplicar a metodologia Seis Sigma, de acordo com as 5 etapas do método DMAIC, para solucionar o problema de elevado custo operacional da flotação. As análises dos dados serão baseadas em análises estáticas feitas com 0 auxílio do software Minitab®, que é 
disponibilizado pela empresa, e os resultados obtidos servirão de base para a tomada de decisão e contribuirão para que o projeto atinja os objetivos propostos.

Figura 1 - Macroprocessos da unidade de estudo.

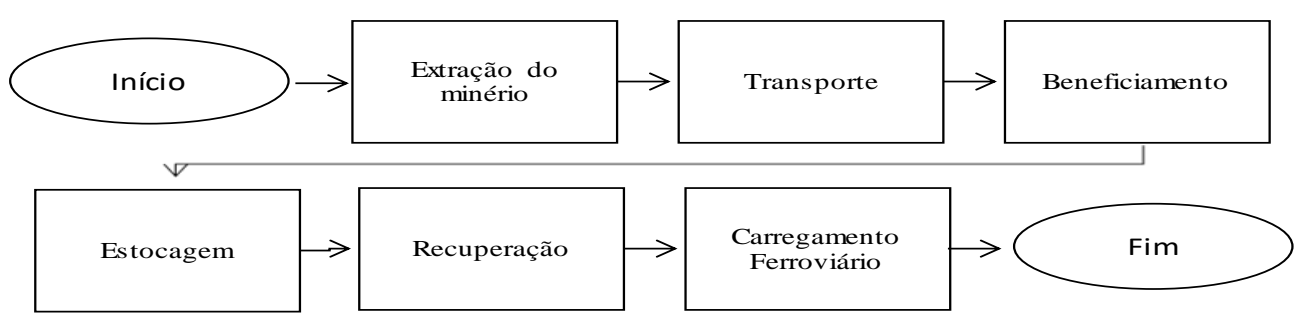

Fonte: Autoria Própria.

De forma geral, inicialmente ocorre a extração do minério na mina, que após a sua extração é transportado, por meio de caminhões fora-de-estrada, até as usinas, onde ocorre o processo de beneficiamento, em que o minério passa por várias etapas até atingir as características necessárias, como por exemplo, referentes à granulometria e ao teor de ferro. Após essa etapa, o produto é colocado nas correias transportadoras e vai para o pátio de estocagem. No pátio, ocorre a recuperação do minério que é direcionado para os silos, onde é feito o carregamento do trem de carga para a expedição do produto. Dentro dos macroprocessos apresentados, a pesquisa apresenta como foco de atuação o processo de beneficiamento dentro da etapa de flotação que está ilustrada na figura 2.

Figura 2 - Macroprocessos da unidade de estudo.

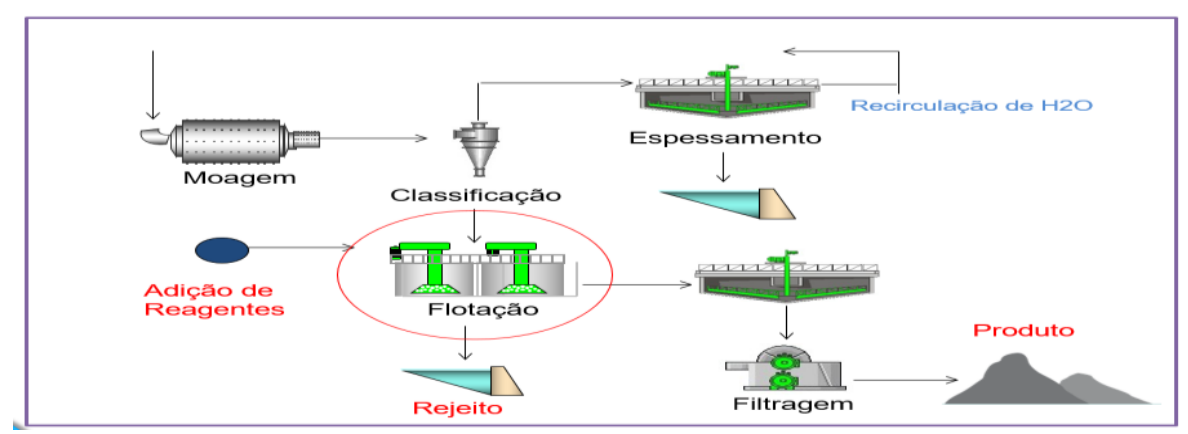

Fonte: Autoria Própria.

A moagem é alimentada com o minério do pátio regulador que possui $60 \%$ de massa retida na tela de $0,15 \mathrm{~mm}$, e após moída, a polpa é classificada em circuito fechado em ciclones de 26 " com partição em massa para overflow de $32 \%$ e $12 \%$ de massa retido na tela de $0,15 \mathrm{~mm}$. Após a classificação, a polpa é deslamada para retirar as partículas ultrafinas, compostas basicamente de alumina (Al2O3) e manganês (MnO). O monitoramento da fração $+0,15 \mathrm{~mm}$ é de suma importância nesta etapa sendo controlado por analisadores de granulometria online e amostragem sistemática pelos responsáveis técnicos para criar parâmetros ótimos de controle garantindo que esta fração não ultrapasse 15\%. A deslamagem é realizada em duas 
etapas, o $1^{\circ}$ estágio opera com ciclones de 20 " e o $2^{\circ}$ com $10^{\prime \prime}$ afim de reduzir os contaminantes (lamas) e recuperar cerca de $88 \%$ de massa.

\section{RESULTADOS E DISCUSSÃO}

\subsection{Etapa Define}

A identificação do problema surgiu através do pilar estratégico da empresa de elevar a margem líquida, qual é impactado diretamente ao custo operacional de cada unidade de produção. O complexo de Itabira possui o maior custo operacional na diretoria com $41 \%$ e destoando das demais, a Unidade Conceição II, com a carteira de insumos, especificamente o reagente químico amina, com 35\% do custo total da Usina. Neste contexto, o escopo do projeto restringe-se ao consumo específico de amina na Usina de Conceição II mantendo a eficiência em qualidade e produção com otimização do consumo do coletor. O período histórico para análise compreende agosto 2014 a setembro 2015, qual nota-se pela figura 3 que a média de consumo de amina era de $134 \mathrm{~g} / \mathrm{t}$ variando de $117 \mathrm{~g} / \mathrm{t}$ a $155 \mathrm{~g} / \mathrm{t} \mathrm{bem} \mathrm{acima} \mathrm{da}$ meta proposta de atingir o consumo de $126 \mathrm{~g} / \mathrm{t}$ até agosto 2016.

Figura 3 - Histórico consumo amina.

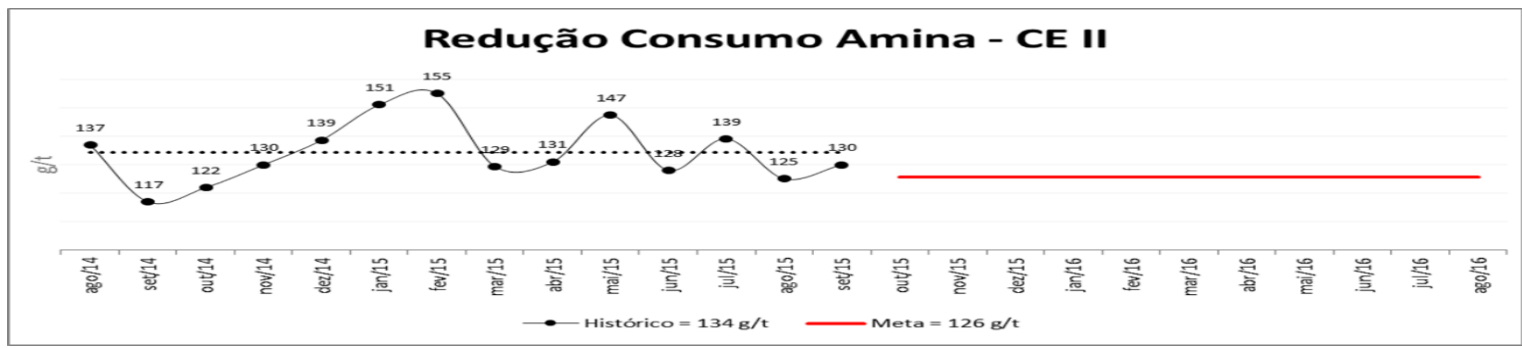

Para verificar a estabilidade dos dados através da carta de controle, testou-se a distribuição normal, qual foi validade pelo p-valor maior do que $5 \%$. E não foi encontrada nenhuma causa especial, sendo o problema sistêmico conforme evidenciado na figura 4.

Figura 4 - Estabilidade dos dados.

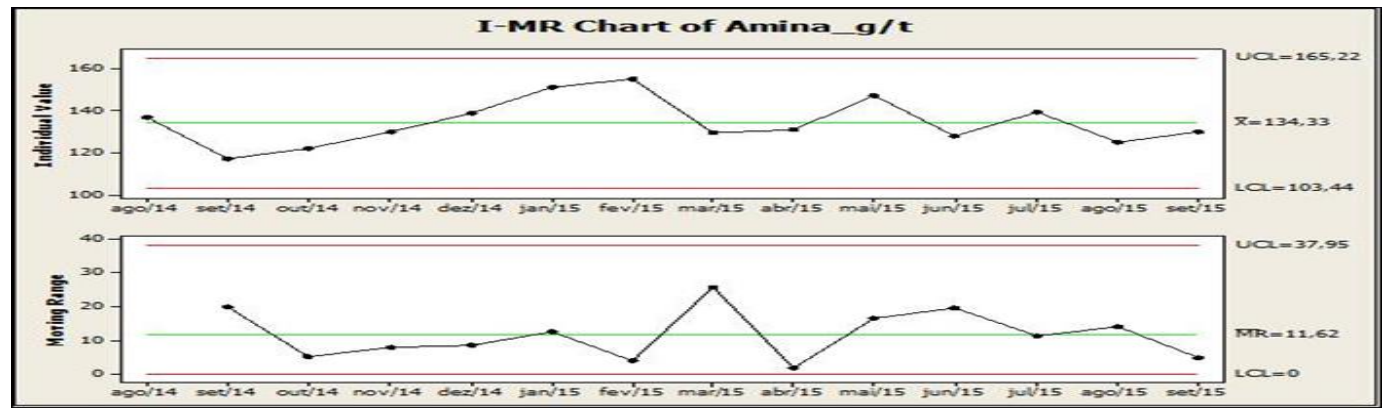

A equipe do projeto propôs o deslocamento da média para elevar os índices de capacidade do processo em virtude do CPK está estatisticamente igual ao PPK (ausência de causas especiais) com nível sigma do processo de 0,7 totalizando $77,54 \%$ de não atendimento à especificação do cliente conforme figura 5 .

Figura 5 - Performance do processo. 


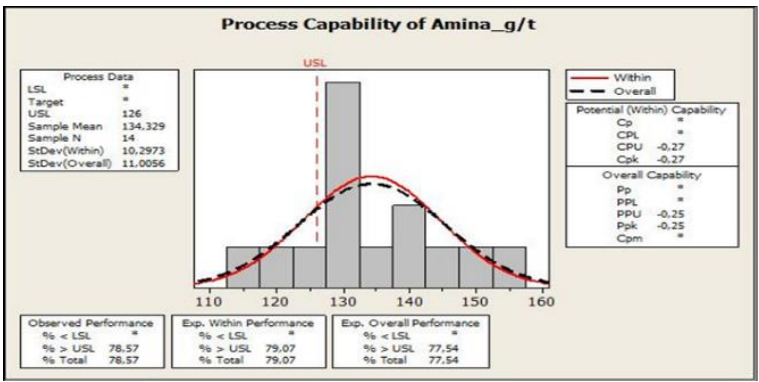

Cálculo da Escala Sigma

\begin{tabular}{|c|c|}
\hline Número de unidades processadas (N) & 14 \\
\hline $\begin{array}{c}\text { Número total de defeitos ou não } \\
\text { conformidades (D) }\end{array}$ & 11 \\
\hline Escala Sigma & 0,7 \\
\hline
\end{tabular}

\subsection{Etapa Measure}

A flotação é um processo de concentração ou separação por diferença de superfície que trabalha com várias variáveis físico-químicas e através da figura 2, nota-se que é possível a influência dos subprodutos dos processos anteriores em sua performance. Para identificar problemas prioritários ou focos de atuação, a equipe do projeto avaliou a similaridade de comportamento entre as linhas através da figura 6 e optou pelo teste de análise variância para comprovar se havia diferença significativa no consumo de amina entre pelo menos uma das três linhas de produção.

Figura 6 - Focos de atuação.
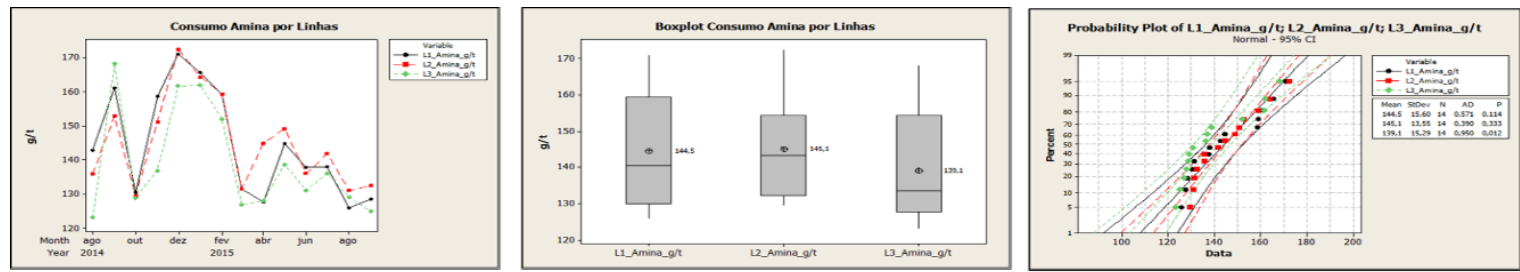

Evidenciado pela figura 7, o teste de hipótese comprovou que não havia diferença significativa entre as linhas tanto em média quanto em variação. Sendo assim, a equipe propôs trabalhar com as 3 linhas de forma igualitária propondo uma meta específica única de $125 \mathrm{~g} / \mathrm{t}$ que sustenta a meta geral de $126 \mathrm{~g} / \mathrm{t}$.

Figura 7 - Análise de variância dos focos de atuação.
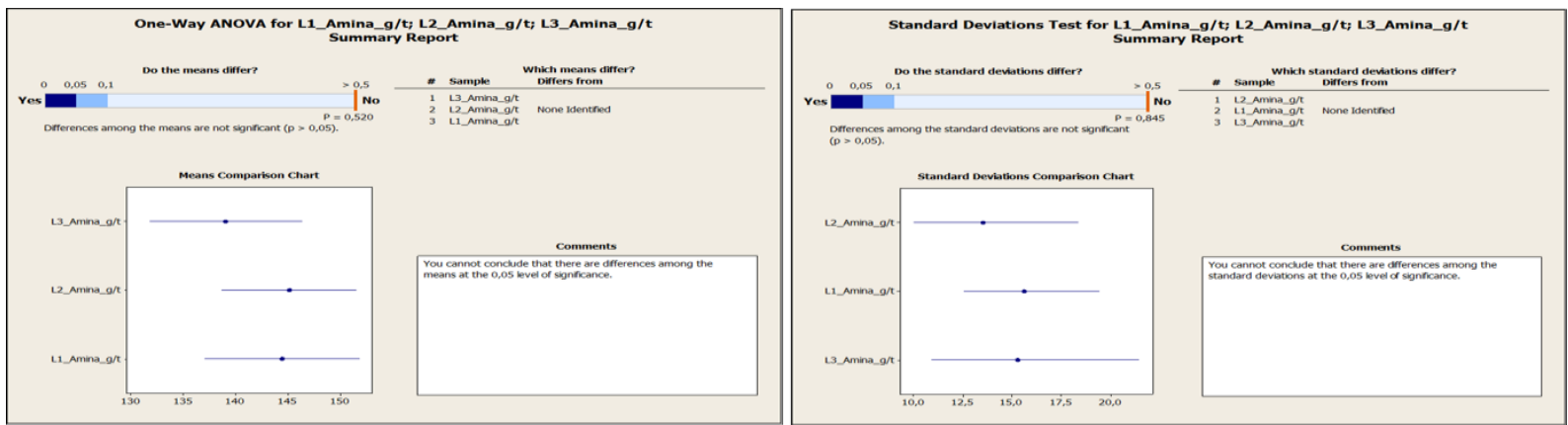

\subsection{Etapa Analyze}

Para compreender o processo, analisar e quantificar as causas que influenciam o consumo de amina, a equipe analisou o fluxograma da flotação e desenhou o mapa de processo conforme figura 8.

Figura 8 - Mapa de processo Usina Conceição II. 

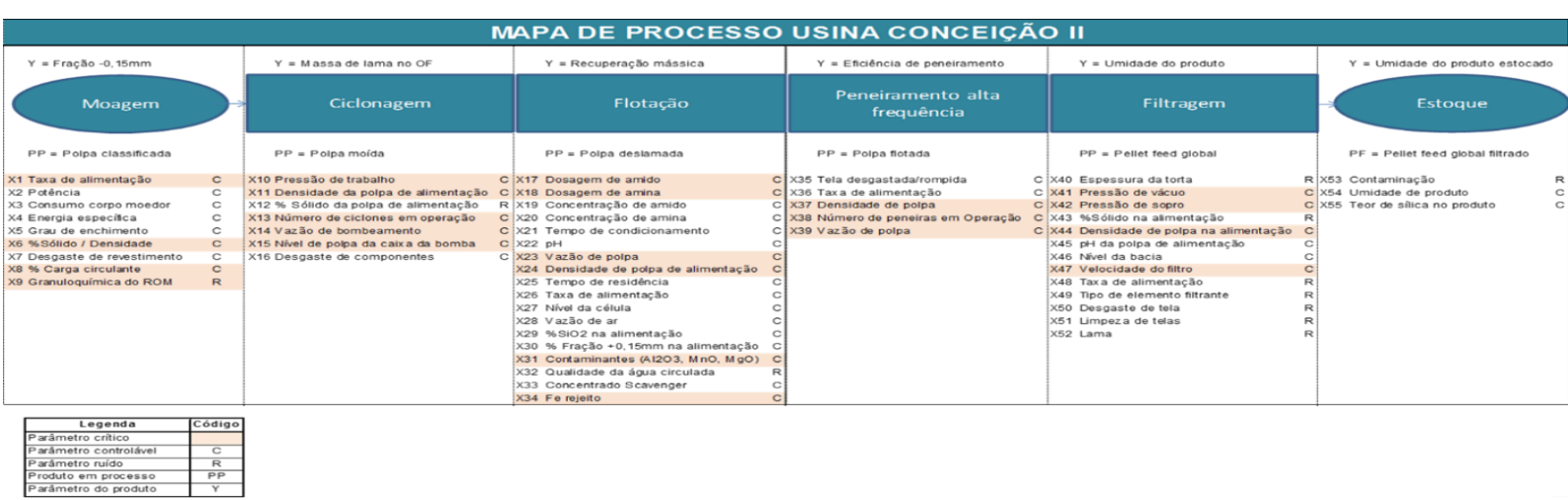

Fonte: Autoria Própria.

Mapeados os parâmetros de processo, as variáveis controláveis e ruídos, a equipe definiu quais era as críticas e aplicaram o diagrama de efeito conforme figura 9 e identificaram possíveis fatores causais. Devido ao número expressivo de fatores a serem estudados, a equipe priorizou através da matriz de esforço e impacto, sendo que este artigo contemplará as causas que foram classificadas como complexas e quantificadas estatisticamente.

Figura 9 - Diagrama causa e efeito.

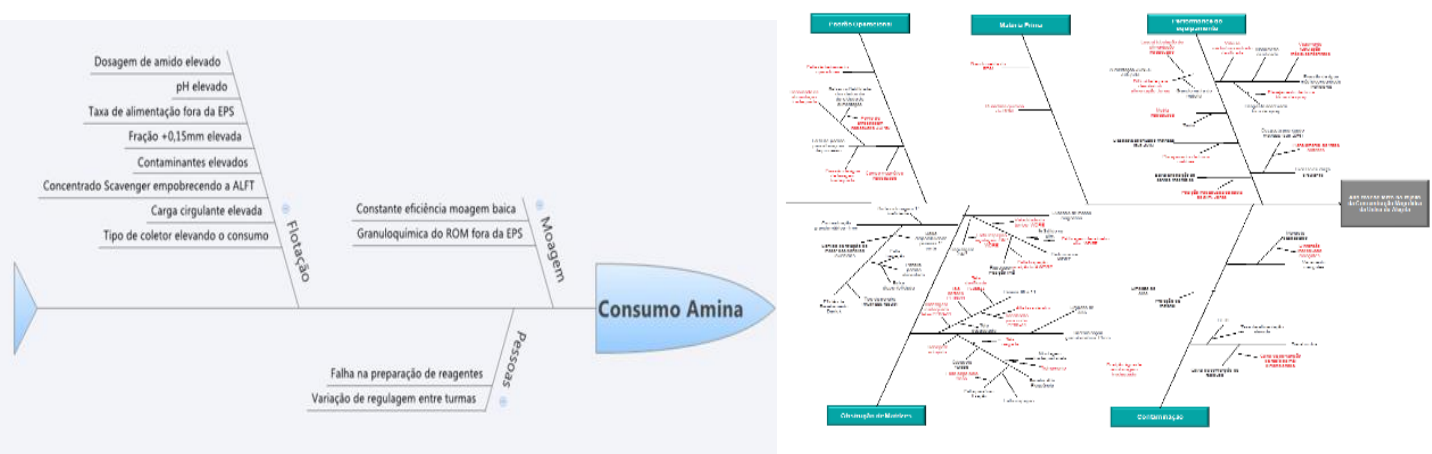

Fonte: Autoria Própria.

A granulometria e o teor de ferro na polpa que alimenta o processo de flotação foram uma das causas analisadas pelo coeficiente de correlação de Pearson, figura 11. No primeiro caso comprova-se a correlação linear positiva através do coeficiente de determinação, $p$-valor $=0$. A medida que a fração maior que 0,15 milímetros aumenta há uma tendência do consumo de amina seguir o mesmo comportamento. Já no segundo caso, a correlação é linear negativa, ao passo que o teor de ferro na polpa de alimentação da flotação aumenta o consumo de amina tende a reduzir.

Figura 10 - Diagrama de dispersão x Correlação Pearson.

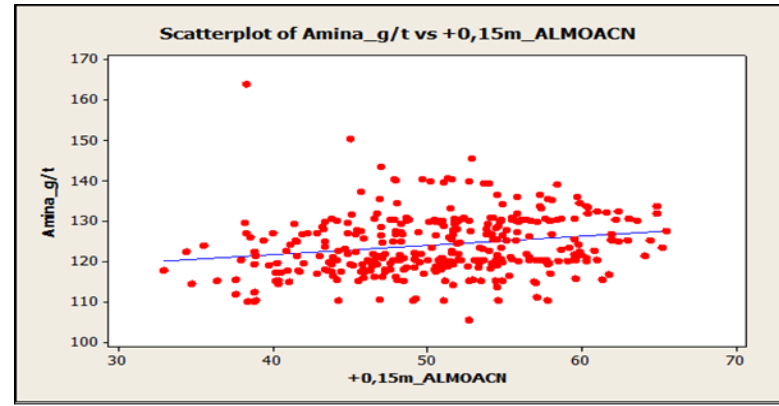

Pearson correlation of Amina_s/t and +0,15m_ALMOACN $=0,210$ P-Value $=0,000$

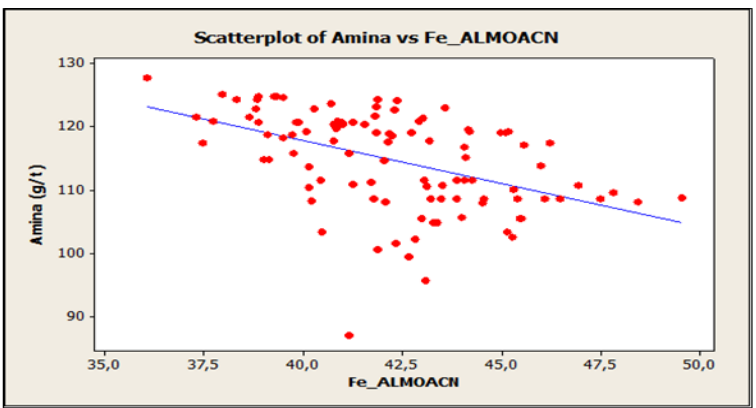

Pearson correlation of Fe_ALMOACN and Amina $=-0,474$ P-Value $=0,000$ 
A causa ilustrada na figura 11 foi um dos paradigmas quebrados na área do objeto de estudo porque as pessoas acreditavam que não havia diferença significativa no modus operandi. Através do teste de hipótese abaixo pode-se afirmar com $95 \%$ de confiança que não há diferença significativa em variabilidade entre as turmas, porém há em média de consumo de amina.

Figura 11 - Análise de variância Turmas.

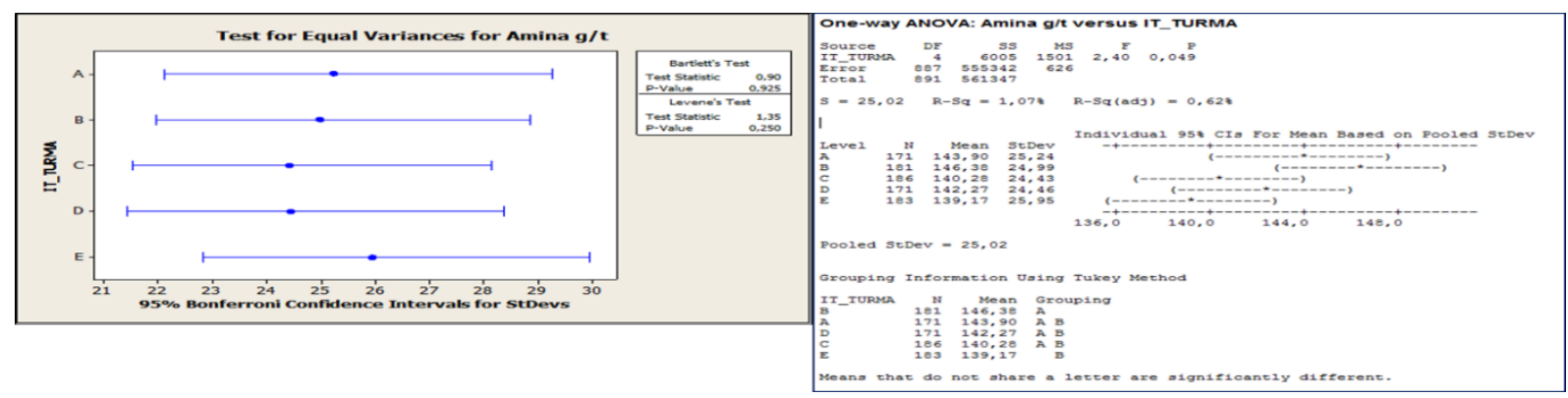

Para identificar a dosagem de amina e fornecedor que atenderia a melhor performance da flotação a equipe definiu o planejamento fatorial, Design of Experiment, com 2 níveis para dosagem de amina $90 \mathrm{~g} / \mathrm{t}$ e $120 \mathrm{~g} / \mathrm{t}$ e 3 tipos de fornecedor. Conforme figura 12, a equipe definiu através dos gráficos de interação que os fornecedores de cor preta e verde atendem as premissas de recuperação metálica e sílica no concentrado com dosagem em $120 \mathrm{~g} / \mathrm{t}$ como referência para o processo de flotação do objeto de estudo.

Figura 12 - Interação dos fatores Design Of Experiment.

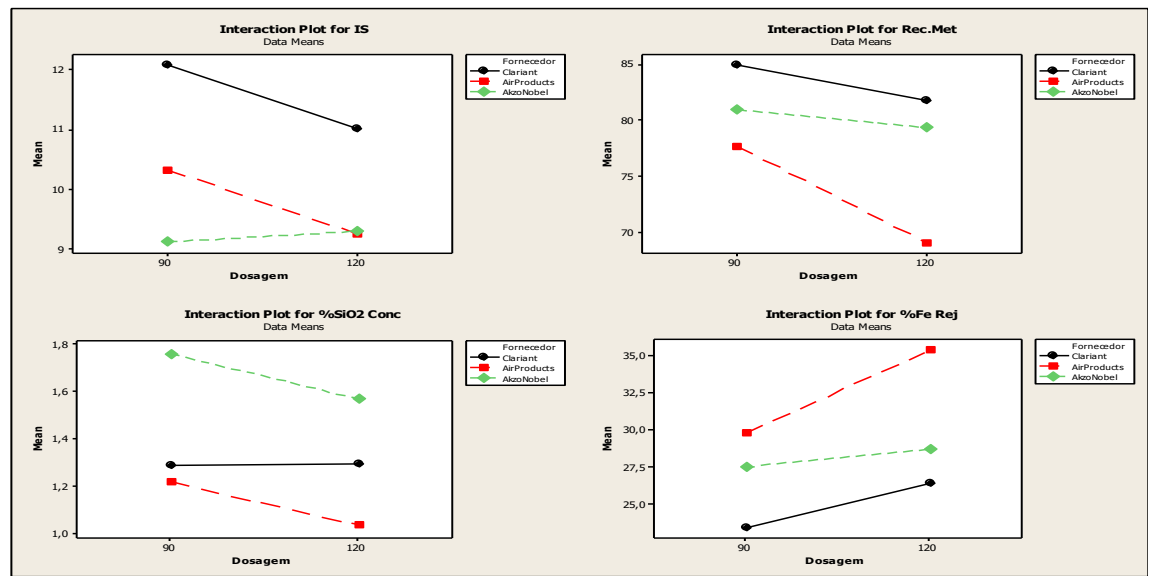

\subsection{Etapa Improve}

Comprovadas as causas complexas e identificadas as causas prioritárias, a equipe propôs várias ações de curto e médio prazo para solucioná-las que foram controladas pelo plano de ação $5 \mathrm{~W} 2 \mathrm{H}$ sendo ilustrado apenas $20 \%$ na figura abaixo: 


\begin{tabular}{|c|c|c|c|c|c|c|c|}
\hline \multicolumn{8}{|c|}{$5 \mathrm{~W} 2 \mathrm{H}$} \\
\hline What? & Causa associada & Who? & When? & Why? & Where? & How? & How much? \\
\hline $\begin{array}{l}\text { Definir cofiguracăai ideal de ciclones } \\
\text { na classificacáa }\end{array}$ & Granulometria (Frą̧äa 0,15mm) & Jülio Ferreira & mar-16 & $\begin{array}{l}\text { Para reduzi r fracáa }+0,15 \mathrm{~mm} \text { na } \\
\text { alimentacáo da flotacáo }\end{array}$ & Usina CE II & Campanha de amostragem & Sem custo \\
\hline 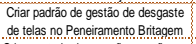 & Granulometria (Frạăa 0,15mm) & Adriano Santos & dez-15 & 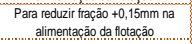 & Peneiramento CE II & Inspeção in loco & Sem custo \\
\hline 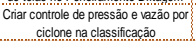 & Granulometria (Frąăa 0,15mm) & Júlio Ferreira & $\operatorname{mar}-16$ & 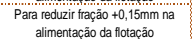 & Usina CE II & Através da automaçăo & Sem custo \\
\hline $\begin{array}{l}\text { Inspecionar semanalmente a } \\
\text { deslamagem }\end{array}$ & Contaminantes (Al203, MnO, MgO) & Ronaldo Galdino & dez-15 & $\begin{array}{l}\text { Para reduziri incidéncia de } \\
\text { contaminantes na flotacăo }\end{array}$ & Usina CE II & Inspeçăa in loco & Sem custo \\
\hline $\begin{array}{l}\text { Amostrar mensalmente a deslamgem } \\
\text { (particâo) }\end{array}$ & Contaminantes (A203, MnO, MgO) & Fábio Lucas & dez-15 & $\begin{array}{l}\text { Acompanhar a performance da } \\
\text { deslamagem }\end{array}$ & Usina CE II & Campanha de amostragem & Sem custo \\
\hline $\begin{array}{c}\text { Criar controle de press ão e vazazo por } \\
\text { nos ciclones automáticos da } \\
\text { deslamegrm }\end{array}$ & Contaminanates (Al203, $\mathrm{MnO}, \mathrm{Mg} 0$ ) & Sirtei Paula & $\operatorname{mar}-16$ & $\begin{array}{l}\text { Para reduziri incidência de } \\
\text { contaminantes na flotaçăo }\end{array}$ & Usina CE II & Atraús da automaagâa & Sem custo \\
\hline Conteiri as concentraçōes na & Má preparaçăo de reagentes & Ana Lacerda & dez -15 & $\begin{array}{l}\text { Para redeuziri a probababilidade de má } \\
\text { preparacáo }\end{array}$ & Usina CE II & Atraús da automaạâli in loco & Sem custo \\
\hline $\begin{array}{l}\text { Operacionalizararacai estagiamento de } \\
\text { amina }\end{array}$ & Má preparaçăa de reagentes & Rodigo Santos & dez-15 & Para reduzir o consumo de amina & Usina CE II & $\begin{array}{l}\text { Atraves de elevantamentito } \\
\text { orçamentáno }\end{array}$ & Sem custo \\
\hline $\begin{array}{l}\text { Instatalar now sistema de dosgem de } \\
\text { amina com concentracăo a } 3 \% \text {. }\end{array}$ & Má preparaçāo de reagentes & Rodigo Santos & mar-16 & Para reduzir o consumo de amina & Usina CE II & $\begin{array}{l}\text { Atraves de levantamentonto } \\
\text { orcamentário }\end{array}$ & Sem custo \\
\hline $\begin{array}{l}\text { Controlar o concentrado do } \\
\text { Scavenger com \% } \% \text { a a } 55 \%\end{array}$ & Variaģa de regulagem entre turmas & Técricos Controle Operacional & dez- 15 & Para reduzir c consumo de amina & Usina CE II & $\begin{array}{l}\text { Regulagem flotacăa confomeme } \\
\text { procediemnto }\end{array}$ & Sem custo \\
\hline $\begin{array}{l}\text { Validar or o tomeciemmito de a anina por } \\
\text { outros fomecedores }\end{array}$ & $\begin{array}{l}\text { Tipo de coletor } \\
\text { Tow }\end{array}$ & Rodrigo Santos & mar-16 & 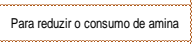 & Usina CE II & $\begin{array}{l}\text { Atraves dos teste de bancada e } \\
\text { validacáo ténica a }\end{array}$ & Em análise \\
\hline
\end{tabular}

Dentre as ações implantadas, destacam-se o gerenciamento da fração $+0,15 \mathrm{~mm}$ dentro dos limites definidos com as análises estatísticas através do plano de inspeção na classificação para garantir o desgaste dos componentes (ápex e vórtex), amostragem sistemática para definir a melhor configuração de potência $x$ carga circulante de operação da moagem, controle de taxa de alimentação na moagem através da análise do $+0,15 \mathrm{~mm}$ online e inclusão de rota de inspeção para os operadores para identificar possíveis contaminações nas bacias de polpa.

\subsection{Etapa Control}

Com a implantação das ações propostas para cada causa identificada dentro dos prazos acordados e mitigados os riscos identificados, o consumo de amina foi reduzindo ao longo do projeto, saindo de $134 \mathrm{~g} / \mathrm{t}$ no período histórico para $128 \mathrm{~g} / \mathrm{t} \mathrm{e}$ durante os meses de validação do projeto atingiu $118 \mathrm{~g} / \mathrm{t}$.

Figura 14 - Evolução do consumo de amina na Usina Conceição II.

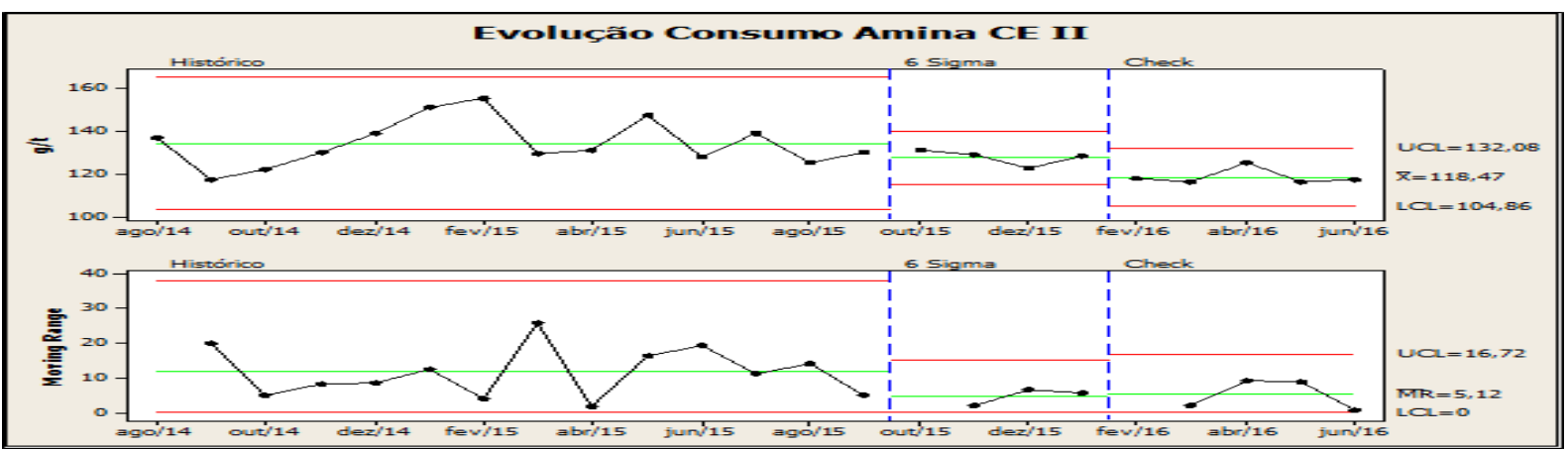

O nível sigma do processo elevou de 0,7 para 3,5 com uma redução de $97 \%$ do percentual fora da especificação conforme figura 15. Sendo este um dos principais resultados deste projeto, qual possibilitou flexibilizar o circuito para atender as especificações do cliente consumindo menos reagente. 
Figura 15 - Nível sigma antes e depois.

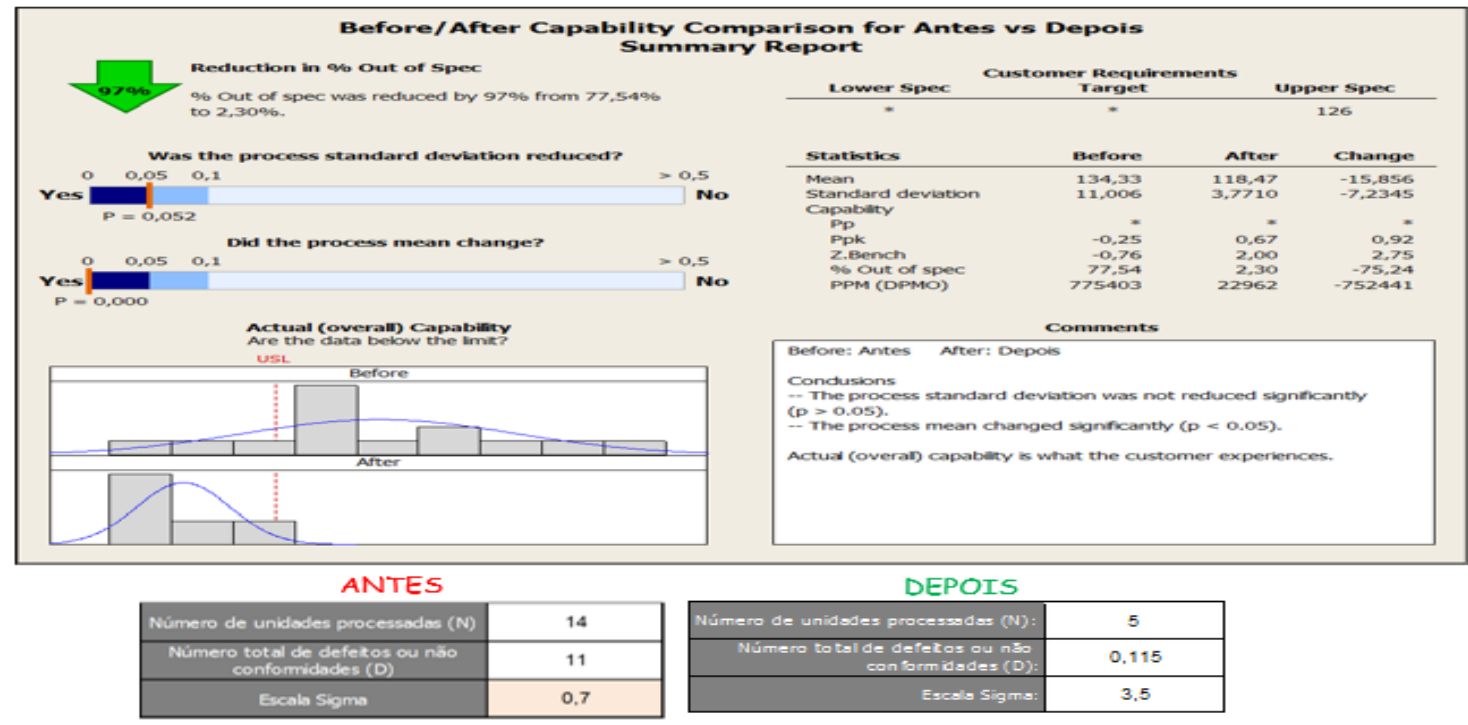

Para controlar as intervenções feitas no processo a equipe revisou quatro procedimentos operacionais e dois procedimentos técnicos, sendo treinado todo público alvo descrito em cada documento. Todas as variáveis estão sendo controladas de forma online pelo sistema da empresa e é aplicado o OCAP, figura 16, quando ocorre qualquer desvio de resultado.

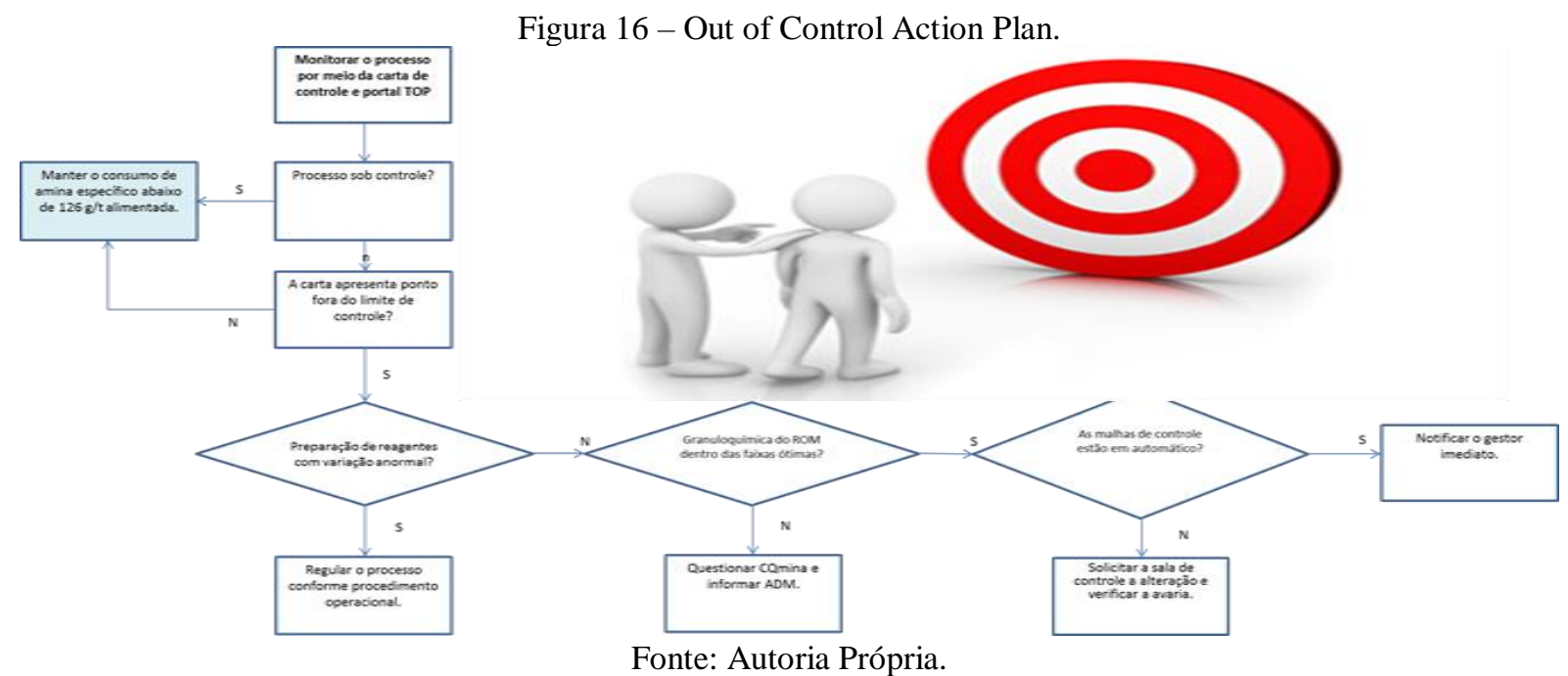

\section{CONCLUSÃO}

O Seis Sigma é uma ferramenta capaz de solucionar problemas e quantificar causas complexas, além de quebrar paradigmas afim de atendar às necessidades do cliente de forma sustentável. A etapa de planejamento e análise são de suma importância para direcionar as ações e recursos de forma inteligente a atender as expectativas e escopo do projeto. As análises estatísticas são de suma importância para definir os parâmetros ótimos de trabalho, conforme figura 17, qual a equipe definiu a região ideal para a granulometria (fração maior que $0,15 \mathrm{~mm}$ ), consumo de amina e qualidade do produto. Esta análise de regiões ótimas foram feitas com todas as variáveis que este projeto definiu como críticas para o processo, gerando uma 
instrução de trabalho, procedimento operacional atreladas ao controle lógico especialista (monitoramento em tempo real).

Figura 17 - Gráfico contorno.

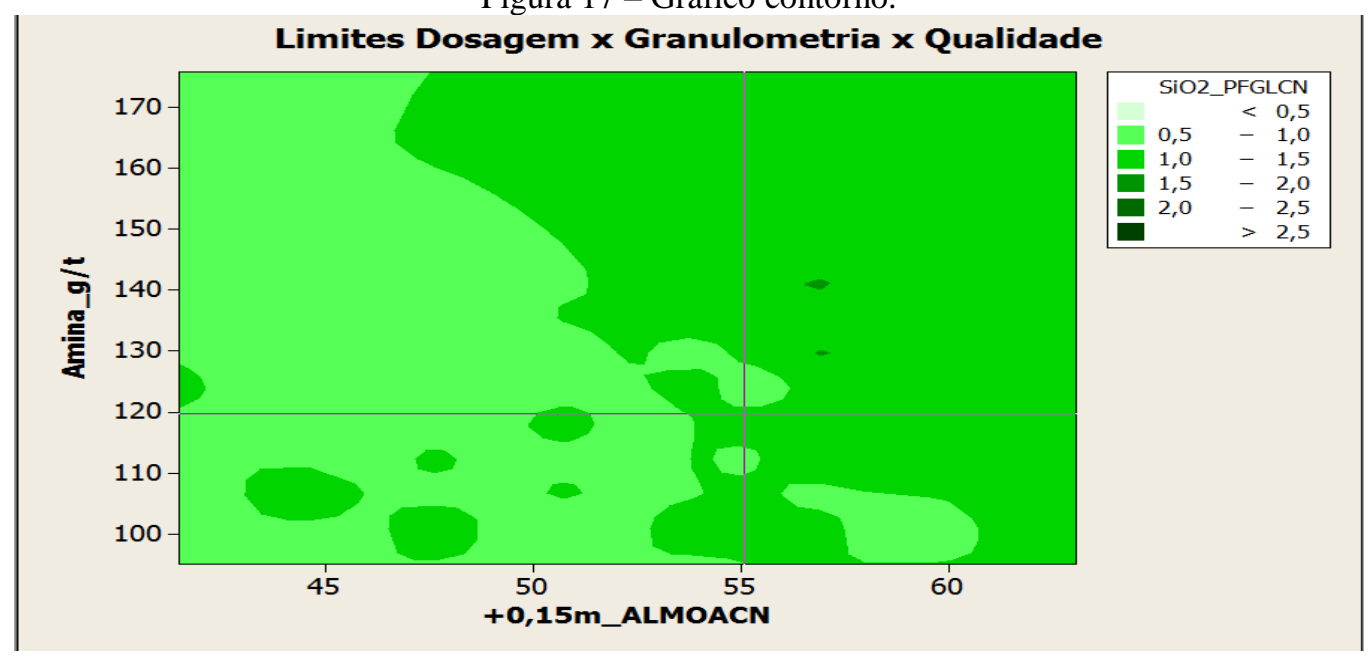

\section{REFERÊNCIAS}

ANDRIETTA, J; MIGUEL, P. A importância do método Seis Sigma na gestão analisada sob uma abordagem teórica. Revista de Ciência e Tecnologia, v. 11, n. 20, 2002.

MELLO, C.; TURRIONI, J.; XAVIER, A.; CAMPOS, D. Pesquisa-ação na engenharia de produção: proposta de estruturação para sua condução. Produção, v.22, n. 1, p.1-13, Jan./Fev. 2012.

MARTINS, M.; SANTOS, A. Modelo de referência para estruturar o Seis Sigma nas organizações. Gestão e Produção, São Carlos, v. 15, n. 1, 2008

PANDE, P. NEUMAN, R. CAVANAGH, R. Estratégia Six Sigma: como a GE, a Motorola e outras grandes empresas estão aguçando o seu desempenho. Rio de Janeiro: Qualitymark, 2007.

PERES, A.E.C. (1996). Flotação. Departamento de Engenharia de Minas, UFMG - Belo Horizonte.

PYZDEK, T.; KELLER, P. O seis sigma: guia do Profissional, um guia completo para Green Belts, Black Belts e gerentes de todos os níveis. 3. ed. Rio de Janeiro: Alta Books, 2011.

SANTOS, A. B. Modelo de referência para estruturar o programa de qualidade seis sigma: proposta e avaliação. São Carlos, 2006. V. 1. Tese - (Doutorado em Engenharia de Produção). Universidade Federal de São Carlos.

WERKEMA, C. Criando a Cultura Lean Seis Sigma. 3 ed. Rio de Janeiro: Elsevier, 2012. YOUSSOUF, A.; RACHID, C.; ION, V. Contribution to the Optimization of Strategy of Maintenance by Lean Six Sigma. Phys. Procedia, v. 55, p. 512-518, 2014. 